\title{
WHO/INRUD patient care and facility-specific drug use indicators at primary health care centres in Eastern province, Saudi Arabia
}

A.A. ElMahalli, ${ }^{1,2}$ O.A.M. Akl, ${ }^{3}$ S.F. Al-Dawood, ${ }^{1}$ A.A. Al-Nehab, ${ }^{1}$ H.A. Al-Kubaish, ${ }^{1}$ S.I. Al-Saeed, ${ }^{1}$ A.A.A. Elkahky ${ }^{4}$ and A.M.A.A. Salem ${ }^{4}$

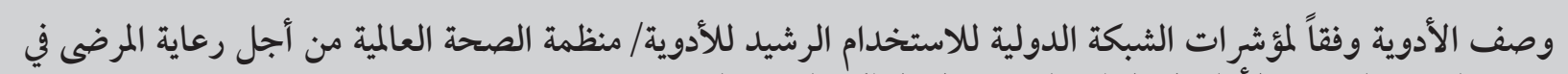

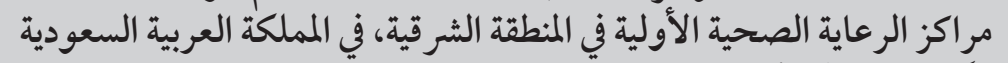

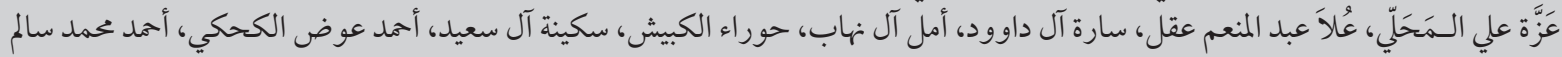

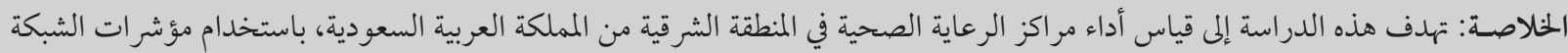

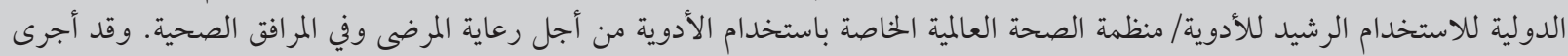

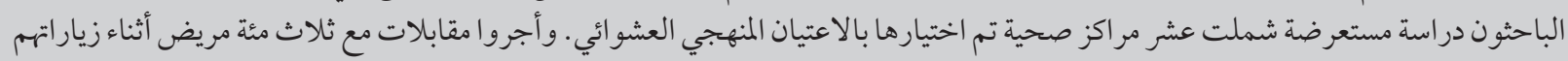

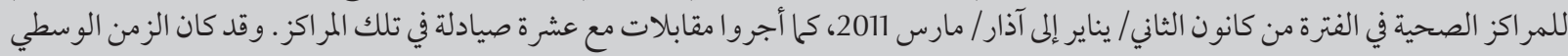

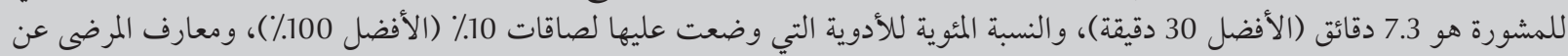

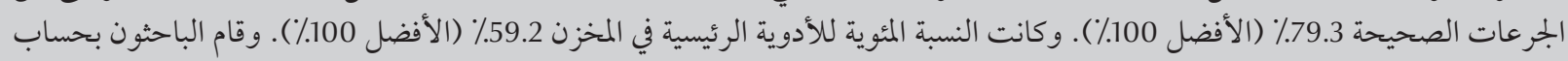

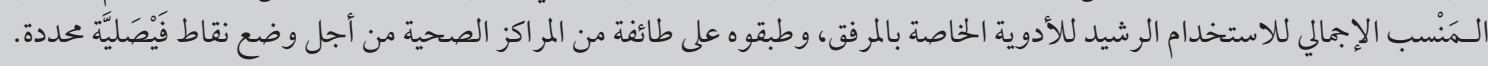

ABSTRACT This study aimed to measure the performance of primary health care centres in Eastern province, Saudi Arabia, using the WHO/International Network of Rational Use of Drugs patient care and facility-specific drug use indicators. In a cross-sectional study, 10 health centres were selected using systematic random sampling. A total of 300 patients were interviewed while visiting the centre from January to March 2011 and 10 pharmacists from the same centres were interviewed. Average consultation time was $7.3 \mathrm{~min}$ (optimal $\geq 30 \mathrm{~min}$ ), percentage of drugs adequately labelled was 10\% (optimal 100\%) and patient's knowledge of correct dosage was $79.3 \%$ (optimal 100\%). The percentage of key drugs in stock was only 59.2\% (optimal 100\%). An overall index of rational facility-specific drug use was calculated and applied to rank the health centres for benchmarking.

Indicateurs OMS/INRUD pour les soins aux patients et l'utilisation des médicaments par les établissements dans des centres de soins de santé primaires de la province orientale de l'Arabie saoudite

RÉSUMÉ La présente étude visait à mesurer les pratiques des centres de soins de santé primaires dans la province orientale de l'Arabie saoudite, à l'aide des indicateurs pour les soins aux patients et l'utilisation des médicaments par les établissements de santé mis au point par l'Organisation mondiale de la Santé et le Réseau international pour l'usage rationnel des médicaments (INRUD). Dans une étude transversale, dix centres de soins de santé ont été sélectionnés par échantillonnage aléatoire systématique. Au total, 300 patients ont été interrogés entre janvier et mars 2011 alors qu'ils consultaient dans un centre, ainsi que 10 pharmaciens dans les mêmes centres. La durée moyenne de consultation était de 7,3 minutes (valeur optimale supérieure ou égale à 30 minutes), le pourcentage des médicaments correctement étiquetés était de 10 \% (valeur optimale $100 \%$ ) et le pourcentage des patients connaissant la bonne posologie était de 79,3\% (valeur optimale $100 \%$ ). Le pourcentage des principaux médicaments en stock était de 59,2 \% (valeur optimale $100 \%$ ). Un indice global d'usage rationnel des médicaments par établissement a été calculé puis appliqué pour le classement des centres de soins de santé à des fins de comparaison.

${ }^{\prime}$ Department of Health Information Management and Technology, College of Applied Medical Sciences, University of Dammam, Dammam, Saudi Arabia (Correspondence to A.A. El Mahalli:aelmahalli90@gmail.com).

${ }^{2}$ Department of Health Administration and Behavioural Sciences; ${ }^{3}$ Department of Primary Health Care, High Institute of Public Health, University of Alexandria, Alexandria, Egypt.

${ }^{4}$ Primary Health Care Department, Ministry of Health, Cairo, Egypt.

Received: 08/07/11; accepted: 11/01/12 


\section{Introduction}

Rational use of medicines for all medical conditions is fundamental to the provision of universal access to adequate health care, satisfaction of health-related human rights and attainment of healthrelated Millennium Development Goals [1-3]. Yet more than $50 \%$ of all medicines worldwide are prescribed, dispensed or sold inappropriately and $50 \%$ of patients fail to take them correctly [2]. About one-third of the world's population lacks access to essential medicines $[1,4]$. Irrational use of medicines can stimulate inappropriate patient demand, and lead to reduced access and attendance rates due to medicine stock-outs and loss of patient confidence in the health system $[2,4]$. The first step to correcting irrational use of medicines is to monitor it in terms of the types of irrational use of medicines (so that strategies can be targeted towards changing specific problems); the amount of irrational use (so that the size of the problem is known and the impact of the strategies can be monitored); and the reasons why medicines are used irrationally (so that appropriate, effective and feasible strategies can be chosen) [1].

There have been studies of prescribing patterns in health car facilities in other parts of the Eastern Mediterranean region. In Bahrain, for example, there was polypharmacy, over-prescribing of antibiotics and under-prescribing of drugs by generic name [5]. In Yemen, the rate of prescribing drugs by generic name was low (39.2\%), the proportion of prescriptions for antibiotics was high (66.2\%) and availability of an essential drugs list (EDL) was only 78.9\% [6]. In a previous paper we reported a survey of rational drug prescribing in 10 primary health care centres (PHCCs) in Eastern province of Saudi Arabia [7]. The study reported here also used the $\mathrm{WHO} /$ International Network of Rational Use of Drugs (INRUD) criteria to assess the performance of the same PHCCs in terms of patient care and facility-specific drug use indicators. We measured some features of health care facilities that impact on rational drug prescribing and some aspects of patient care that reflect the time given for diagnosis and ensuring patients are well informed about the prescribed drugs. These would be used to identify whether a facility was exceeding or under-performing these defined norms of practice and to obtain baseline information for continuous monitoring.

\section{Methods}

\section{Study design and setting}

This was a cross-sectional study carried out in 10 PHCCs from the Eastern province, selected based on systematic random sampling to represent the 13 districts of the province.

\section{Sample}

For the patient care indicators a sample of 30 patients per PHCC who attended for diagnosis and treatment of general illnesses during the period January to March 2011 were included. They represented a mix of health problems and ages. Patients selected in the study were spread throughout the clinic day. Therefore a total of 300 patients were included. For the facility-specific indicators a pharmacist from each PHCC was interviewed during the survey visit. Therefore 10 pharmacists were interviewed.

\section{Data collection}

Formal approval from the Ministry of Health in Saudi Arabia was taken before conducting the research. Confidentiality of the data collected was maintained throughout.

Patients were observed and interviewed during the survey visit to obtain the required variables and pharmacists were interviewed and their dispensing practices observed.

A standard patient care and facility indicators form was used to collect the required variables [8,9]. Data collectors at all PHCCs followed the WHO guidelines and methods to ensure reliability of data collection. A pilot study was conducted in which 15 patients from 2 different centres were interviewed to ensure availability of the required data, to estimate the time required to collect the variables from each patient and to edit the data collection tool as needed. The following WHO/INRUD patient care and facility-specific drug use indicators were used and were calculated using standard methods [8,9]:

\section{Patient care indicators}

- Average consultation time with patients by physicians. Optimal level: $\geq$ $30 \min [10]$.

- Average dispensing time taken with patients. Optimal level: $\geq 60 \mathrm{~s}$.

- Percentage of prescribed drugs actually dispensed at health facility. Optimal level: 100\%.

- Percentage of drug packages actually labelled with at least 2 items (out of patient name, drug dose and drug regimen). Optimal level: 100\%.

- Percentage of patients knowledgeable about the correct dosage schedule for all drugs dispensed. Optimal level: $100 \%$.

\section{Facility-specific indicators}

- Availability of copy of national essential drug list (EDL) or local formulary at health facility (yes/no). Optimal level: 100\% (yes $=100 \%$; no $=0 \%$ ).

- Percentage of key drugs to treat important conditions actually in stock at health facility. Optimal level: 100\%.

\section{Data analysis}

As described in our other paper on the subject [7], indices were calculated for each patient care indicator by dividing the optimal values by the actual values obtained. All the indicators had the same optimal index of 1: the closer to 1 , the more rational a drug use indicator. Then a total rational facility-specific drug use (IRFSDU) was calculated for 
each health centre by adding the indices. This enabled them to be ranked in order to identify the PHCC with the highest score to be used for benchmarking.

Data entry and analysis were conducted using SPSS, version 19. Descriptive statistics were used in the form of mean, median and standard deviation (SD). Differences between PHCCs were measured using ANOVA. The statistical significance was determined by a $P$-value $<0.05$.

\section{Results}

\section{Patient care indicators}

The mean consultation time for the 10 PHCCs was 7.3 (SD 5.7) min, range 4.6-12.6 min, and the mean dispensing time was 100 (SD 146) s, range 58-180 s (Table 1 ). The mean percentage of drugs actually dispensed was $99.6 \%$ (SD 3.7\%), ranging from 98.8\%-100\%, but the proportion of drugs adequately labelled was only $10.0 \%$ (SD 30.1\%) and ranged widely across the 10 PHCCs from 0-100\%. The percentage of patients with knowledge of the correct dosage ranged from 53.3\%-93.3\%, with a mean of $79.3 \%$ (SD $40.6 \%$ ). The difference between the PHCCs was significant for all patient care indicators, except the percentage of drugs dispensed (Table 1).

Among the PHCCs, centre number 4 had the highest rank for IRPCDU for patient care indicators (Table 2).

\section{Facility-specific indicators}

All but 1 PHCC centre had a copy of the EDL, i.e. scored $100 \%$ or this variable (Table 1), and therefore the overall mean availability was $90 \%$ over the 10 centres ( scoring available $=100 \%$ and not available $=0 \%)$. The percentage of key drugs in stock was ranged from $33.3 \%-75.0 \%$, with a mean of $59.2 \%$ (SD 12.0\%).

Among PHCCs, centres number 4 and 10 were jointly ranked the highest rank for IRFSDU for facility-specific indicators (Table 2).

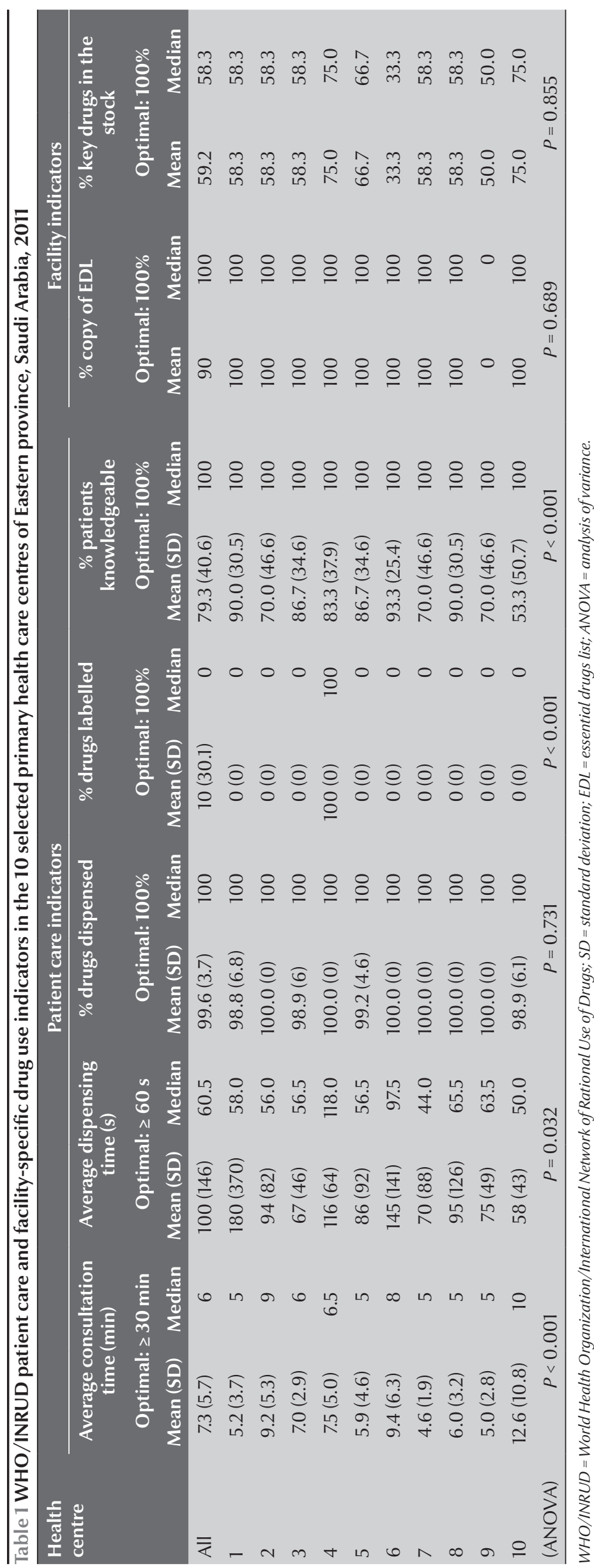




\begin{tabular}{|c|c|c|c|c|c|c|c|c|c|}
\hline \multicolumn{10}{|c|}{$\begin{array}{l}\text { Table } 2 \text { Index of rational patient care } \\
\text { Eastern province, Saudi Arabia, } 2011\end{array}$} \\
\hline \multirow{2}{*}{$\begin{array}{l}\text { Health } \\
\text { centre }\end{array}$} & \multicolumn{6}{|c|}{ Patient care indicators } & \multicolumn{3}{|c|}{ Facility indicators } \\
\hline & $\begin{array}{l}\text { Consultation } \\
\text { time index }\end{array}$ & $\begin{array}{l}\text { Dispensing } \\
\text { time index }\end{array}$ & $\begin{array}{c}\text { Dispensing } \\
\text { drugs } \\
\text { index }\end{array}$ & $\begin{array}{l}\text { Labelled } \\
\text { drugs } \\
\text { index }^{\mathrm{a}}\end{array}$ & $\begin{array}{c}\text { Patients' } \\
\text { knowledge } \\
\text { index }^{\mathrm{a}}\end{array}$ & IRPCDU $^{\mathrm{b}}$ & $\begin{array}{l}\text { Index of } \\
\text { EDL }^{\mathrm{a}}\end{array}$ & $\begin{array}{l}\text { Index of } \\
\text { key drugs } \\
\text { in stock }\end{array}$ & IRFSDU ${ }^{\mathrm{c}}$ \\
\hline 1 & 0.17 & 1 & 0.99 & 0 & 0.90 & 3.06 & 1 & 0.58 & 1.58 \\
\hline 2 & 0.31 & 1 & 1 & 0 & 0.70 & 3.01 & 1 & 0.58 & 1.58 \\
\hline 3 & 0.23 & 1 & 0.99 & 0 & 0.87 & 3.09 & 1 & 0.58 & 1.58 \\
\hline 4 & 0.25 & 1 & 1 & 1 & 0.83 & 4.08 & 1 & 0.75 & 1.75 \\
\hline 5 & 0.20 & 1 & 0.99 & 0 & 0.87 & 3.06 & 1 & 0.67 & 1.67 \\
\hline 6 & 0.31 & 1 & 1 & 0 & 0.93 & 3.24 & 1 & 0.33 & 1.33 \\
\hline 7 & 0.15 & 1 & 1 & 0 & 0.70 & 2.85 & 1 & 0.58 & 1.58 \\
\hline 8 & 0.20 & 1 & 1 & 0 & 0.90 & 3.10 & 1 & 0.58 & 1.58 \\
\hline 9 & 0.17 & 1 & 1 & 0 & 0.70 & 2.87 & 0 & 0.50 & 0.50 \\
\hline 10 & 0.42 & 0.97 & 0.99 & 0 & 0.53 & 2.91 & 1 & 0.75 & 1.75 \\
\hline
\end{tabular}

${ }^{a}$ Optimal index $=7 ;{ }^{b}$ Maximum IRDP $=5 ;{ }^{c}$ Maximum IRDP $=2$. $E D L=$ essential drugs list.

\section{Discussion}

\section{Patient care indicators}

Irrational use of drugs occurs in all countries and causes harm to people [11]. The results of the present study demonstrated that the average consultation time was short, at $7.3 \mathrm{~min}$. The difference between PHCCs regarding average consultation time was significant. The average consultation times reported from other developing countries are even lower, ranging from $2.8-7$ $\min [12-15]$. In a study conducted in 21 PHCCs of Jordan, it was $3.9 \mathrm{~min}$ [16] and in Kuwait it was $2.8 \mathrm{~min}$ [17]. These times and ours are well below the optimal consultation time of $\geq 30$ minutes recommended for conducting proper history-taking, complete physical examination, appropriate health education instructions and prescribing therapy. The short times reported at PHCCs in this study could be due to a high workload of patients per physician and this requires further investigation.

The average dispensing time reported in this study (99.6s) was longer than the optimal dispensing time of $\geq$ $60 \mathrm{~s}$. There was a wide range of average dispensing times from $58-180 \mathrm{~s}$ and the difference between PHCCs was significant. This average time was also longer than that reported in studies conducted at PHC facilities in Jordan (28.8 s) [16] and in Kuwait (54.6 s) [17]. A dispensing time $<60 \mathrm{~s}$ is insufficient by WHO criteria to explain the dosage regimen, adverse effects of drugs, all precautions and actually label and dispense a drug. Patient compliance directly depends on his/her knowledge about the drug [2] and therefore an adequate dispensing time is a necessary step towards improving patient care. The long dispensing time at this study can be attributed to the fact that most dispensary personnel checked the prescriptions against patient's complaints before dispensing drugs and in suspected cases they rechecked with the physician regarding the drug type and its dose.

The percentage of prescribed drugs actually dispensed was high (99.6\%), close to the optimal value of $100 \%$. This value is approximately similar to that in Kuwait 97.9\% [17]. An inadequate drug supply has implications for patients' health status, is inconvenient for patients and jeopardizes their trust in the health system [2].

WHO recommends that each drug label should contain the dose regimen, patient name and drug dose [8]. In this study, drug labelling practice (2 out of 3 items) was very poor, only $10 \%$, compared with an optimal value of $100 \%$. The percentage of drugs labelled ranged from $0 \%$ to $100 \%$ across the 10 PHCCs and there was a statistically significant difference between them. This can be attributed to the lack of a labelling system where dispensary personnel only write the frequency of administration of each drug on the pillbox or medicines bag. Only PHCC number 4 practised good labelling. The poor labelling reported in this study is comparable with the results of the study in Kuwait where $66.9 \%$ were adequately labelled. [17].

Patient's knowledge of the correct dosage was low (79.3\%) compared with the optimal value of $100 \%$. The difference between health centres was not significant. This result was approximately similar to that of Jordan where the mean patient knowledge of prescribed drug dose was $77.7 \%$ [16]. However, it was comparable to that conducted in Kuwait where only $26.9 \%$ of patients demonstrated adequate knowledge of all drugs dispensed for them [17]. Patient's knowledge of the correct dosage is highly beneficial to avoid drug 
overuse and abuse and prevent adverse effects that harm patients' health status.

PHCC number 4 had the highest IRPCDU for patient care indicators, so could be considered as benchmarking for the remaining centres.

\section{Facility indicators}

The results for the facility indicators showed that only 1 PHCC had no EDL/formulary available, and therefore the average availability over the 10 centres was 90\%. In Yemen, a study reported that the EDL was only available in $78.9 \%$ of health facilities at different levels [6]. However, in Gaza Strip a copy of the EDL was only available in 28.3\% of clinics [18]. WHO recommends adherence of physicians to the drug listed in the EDL/formulary when prescribing medications in order to ensure effective health care for all [9].
The mean percentage of key drugs in stock was very low (59.2\%) compared with the optimal value of $100 \%$. However, it was lower than that in Gaza Strip, where the availability of key drugs was $82.6 \%$ [18]. A shortage of supplies of essential drugs that treat common health problems is harmful to the health status of patients [10].

PHCCs numbers 4 and 10 jointly had the highest IRFSDU for facility indicators and can be considered as benchmarking for the remaining centres.

\section{Conclusion and Recommendations}

This study measured the performance of PHCCs in Eastern province of Saudi Arabia using the WHO/INRUD patient care and facility-specific drug use indicators. Concerning patient care indicators, the results were far from the optimal values, especially for average consultation time, drug labelling and patients' knowledge of correct dose. With regards to facility-specific indicators the results were especially disappointing for the proportion of key drugs in stock.

We recommend that consultation times need to be longer and reasons for the short times need to be investigated. Drug labelling systems need to be improved to include drug regimen, patient name and drug dose, and the availability of key drugs in the PHCCs' stocks needs to be improved. Consideration should be given to using the highest ranked health centres as benchmarks for other PHCCs in the region.

\section{References}

1. Council of Churches. Promoting rational use of medicine. Contact, 2006, 183:1-19.

2. Promoting rational use of medicines: core components. Geneva, World Health Organization, 2002 (WHO Policy Perspectives on Medicines No. 5).

3. Management sciences for health. Managing drug supply. West Hartford, Connecticut, Kumarian Press, 1997.

4. Le Grand A, Hogerzeil HV, Haaijer-Ruskamp FM. Intervention research in rational use of drugs: a review. Health Policy and Planning, 1999, 14:89-102.

5. Otoom $\mathrm{S}$ et al. Analysis of drug prescriptions in primary health care centers in Bahrain. Eastern Mediterranean Health Journal, 2007, 16:511-515.

6. Bashrahil KA. Indicators of rational drug use and health services in Hadramout, Yemen. Eastern Mediterranean Health Journal, 2010, 16:151-155.

7. El Mahalli AA. WHO/INRUD drug prescribing indicators at primary health care centres in Eastern province, Saudi Arabia. Eastern Mediterranean Health Journal, 2012, 12(11):1091-1096.

8. How to investigate drug use in health facilities: selected drug use indicators. Geneva, World Health Organization, 1993 (EDM Research Series No. 007).

9. How to investigate drug use in health facilities. Action program on essential drugs. Geneva, World Health Organization, 1995.
10. Medicines: rational use of medicines. Fact sheet No. 338. World Health Organization [online] (http://www.who.int/mediacentre/factsheets/fs338/en/, accessed 16 September 2012).

11. Session guide. Implementing a drug use indicators study. World Health Organization [online] (http://archives.who.int/prduc2004/rducd/Session_Guides/implementing__sg.htm, accessed 18 September 2012).

12. Bannenberg WJ et al. Evaluation of the Nile province essential drugs project. Geneva, World Health Organization, 1991 (WHO/DAP/91.10).

13. Ofori-Adjei D. Report on Tanzania field test. INRUD News, 1992, 3:9.

14. Hogerzeil HV et al. Impact of an essential drugs programme on availability and rational use of drugs. Lancet, 1989, 1:141-142.

15. Bimo. Report on Nigeria field test. INRUD News, 1992, 3:9-10.

16. Otoom $\mathrm{S}$ et al. Evaluation of drug use in Jordan using WHO patient care and health facility indicators. Eastern Mediterranean Health Journal, 2002, 8(4-5):544-549.

17. Awad A, Al-Saffar N. Evaluation of drug use practices at primary healthcare centers of Kuwait. European Journal of Clinical Pharmacology, 2010, 66(12):1247-1255.

18. Fattouh R, Abu Hamad B. Impact of using essential drug list: analysis of drug use indicators in Gaza Strip. Eastern Mediterranean Health Journal, 2010, 16(8):886-892. 